\section{Genome Sequence of Venturia carpophila, the Causal Agent of Peach Scab}

\author{
Yang Zhou, ${ }^{1,2}$ Lei Zhang, ${ }^{3}$ Fei Fan, ${ }^{1,2}$ Zuo-Qian Wang, ${ }^{4}$ Yue Huang, ${ }^{1}$ Liang-Fen Yin, ${ }^{2}$ Wei-Xiao \\ Yin, ${ }^{2}$ and Chao-Xi Luo ${ }^{1,2,+}$ \\ ${ }^{1}$ Key Lab of Horticultural Plant Biology, Ministry of Education, Huazhong Agricultural University, \\ Wuhan 430070, China \\ ${ }^{2}$ College of Plant Science and Technology, Huazhong Agricultural University, Wuhan 430070 , \\ China \\ ${ }^{3}$ Wuhan Institute of Virology, Chinese Academy of Sciences, Wuhan 430071, China \\ ${ }^{4}$ Institute of Plant Protection and Soil Fertilizer, Hubei Academy of Agricultural Science, Wuhan \\ 430064, China
}

\begin{abstract}
Venturia carpophila, the causal agent of scab disease on peach, is a host-specific fungus that is widely distributed around the world, including China. In our previous study, samples were collected from 14 provinces in China, and 750 isolates were obtained by single-spore separation. Here, we reported the first highly contiguous whole-genome sequence $(35.87 \mathrm{Mb})$ of the $\mathrm{V}$. carpophila isolate $\mathrm{ZJHZ1-1-1}$, which included 33 contigs with $\mathrm{N}_{50}$ value of $2.01 \mathrm{Mb}$ and maximum contig length of $3.39 \mathrm{Mb}$. The high-quality genome sequence and annotation resource will be useful to study the fungal biology, pathogen-host interaction, fungicide resistance, characterization of important genes, population genetic diversity, and development of molecular markers for genotyping and species identification.
\end{abstract}

\section{Genome Announcement}

Peach scab, caused by Venturia carpophila (syn. Cladosporium carpophilum, Fusicladosporium carpophilum), is a common and widespread fungal disease in peach-growing regions in China (Chen et al. 2018; Schubert and Braun 2004). V. carpophila is a pathogenic fungus that belongs to the phylum Ascomycota, order Pleosporales in family Venturiaceae. In general, Venturia species are host-specific pathogens and each can only infect one plant species or close relatives in a given host family (González-Dominguez et al. 2017). It was reported that $V$. carpophila could also cause apricot scab and plum scab (Bensch et al. 2003; Kim et al. 2017; Schnabel and Layne 2004). Although its sexual stage has been described on overwintered apricot leaves in Australia (Fisher 1961), it has not been found on peach. Peach scab generally produces dark brown to black freckles, spots, or scabs of variable size on the fruit surface. Lesions on fruits are oval or circular, approximately 2 to $5 \mathrm{~mm}$ in diameter (Chen et al. 2014; Scherm et al. 2008). Leaf symptoms are less common and are not obvious but occur as yellowish blotches that turn grayish as spores are produced, with lesions most often on the back of the leaf (Chen et al. 2014). The disease is particularly

\footnotetext{
${ }^{\dagger}$ Corresponding author: C.-X. Luo; cxluo@mail.hzau.edu.cn
}

*The $e$-Xtra logo stands for "electronic extra" and indicates there is supplementary material published online.

The author(s) declare no conflict of interest.

Accepted for publication 28 February 2021.

\section{$e-\mathbf{X t r a}^{*}$}

\section{Funding}

This work is supported by China Agriculture Research System (grant number CARS-30).

\section{Keywords}

fungal pathogen, genome, peach scab disease, Venturia carpophila 
severe in temperate climate regions characterized by high humidity, cool spring weather, and poor air circulation. Fruit infection by $V$. carpophila can significantly reduce both fruit yield and quality and result in considerable economic losses (Schnabel and Layne 2004).

To date, eight members of the genus Venturia have been sequenced and there are more than 102 genome assemblies available for Venturia spp., including $V$. effusa (GCA_007735645.1), V. inaequalis (QFBF00000000), V. asperata (QWWL00000000), V. pirina (JEMP00000000), V. nashicola (VCHV00000000), V. aucupariae (QWZN00000000), V. oleaginea (JABMLP000000000), V. carpophila (MECS00000000), the causal agents of pecan scab (V. effusa), apple scab ( $V$. inaequalis and $V$. asperata), pear scab (V. pirina and V. nashicola), sorbus scab (V. aucupariae), olive leaf scab (V. oleaginea), and peach scab (V. carpophila) (Bock et al. 2016; Chen et al. 2017; Cooke et al. 2014; Jaber et al. 2020; Johnson et al. 2019; Le Cam et al. 2019; Lichtner et al. 2020; Shiller et al. 2015). Among them, the best studied and most economically important species is $V$. inaequalis, with 88 genome assemblies reported. $V$. effusa genomic sequence is of highest stitching quality and is also the first chromosomal-level assembly among Venturia species (Winter et al. 2020). In contrast, fewer studies have been performed for other related Venturia species. In V. carpophila, only one United States isolate genome was deposited in the GenBank database (accession MECS00000000). The complete genome sequences of V. carpophila isolates from China remain to be determined and the genomic differences between Chinese isolates and other isolates are still unclear. In addition, the first reported genome assembly from the United States seems to be highly fragmented (657 scaffolds) (Chen et al. 2017). Here, we report the complete whole-genome sequence for the Chinese V. carpophila isolate ZJHZ1-1-1, aiming to provide better $V$. carpophila genome assembly and annotations.

Peach scab samples were collected from 14 provinces in China and 750 isolates were obtained, as described previously (Zhou et al. 2021). Among them, the isolate ZJHZ1-1-1 grew fast on oatmeal agar medium and showed high virulence in field inoculation experiments and was thus used for sequencing. Briefly, asexually produced conidia were scraped from a single lesion on the fruit surface using a scalpel and was then spread on the water agar (20 g of agar per liter) plates. Using a modified microscope (Goh 1999), a single spore was picked with a glass needle from water agar plates and was then transferred to potato dextrose agar (200 g of potato, $20 \mathrm{~g}$ of dextrose, and $20 \mathrm{~g}$ of agar per liter) amended with lactic acid ( $0.50 \mathrm{ml}$ per liter), streptomycin ( $0.20 \mathrm{~g}$ per liter), tetracycline $(0.05 \mathrm{~g}$ per liter), and chloramphenicol (0.05 g per liter) (Chen et al. 2018). Mycelial suspension of $V$. carpophila was transferred to $50 \mathrm{ml}$ of antibiotic-amended malt extract broth $(30 \mathrm{~g}$ of malt extract and 5 $\mathrm{g}$ of peptone per liter) in an Erlenmeyer flask in the dark, with shaking at $21^{\circ} \mathrm{C}$ for 10 days, to culture sufficient quantities of mycelium for DNA extraction. Genomic DNA was extracted with the modified sodium dodecyl sulfate method (Hu et al. 2004) and was quantified with a Qubit 2.0 Fluorometer (Thermo Scientific). For isolate identification, we used primer pairs ITS4/ITS5 and LROR/LR5 to amplify the internal transcribed spacer (ITS) region and the complete large subunit ribosomal RNA gene (LSU), respectively (Vilgalys and Hester 1990; White et al. 1990). The ITS and LSU sequences of ZJHZ1-1-1 have been deposited in GenBank (MN958609 and MT772296). The whole genome of ZJHZ1-1-1 was sequenced using PacBio Sequel and Illumina NovaSeq PE150 platforms at the Beijing Novogene Bioinformatics Technology Co., Ltd. PacBio Sequel platform libraries for single-molecule real-time (SMRT) sequencing was constructed with an insert size of $20 \mathrm{~kb}$, using the SMRTbell TM Template kit, version 1.0. Illumina NovaSeq platform libraries for sequencing were generated with an insert size of $350 \mathrm{~kb}$, using a NEBNext Ultra DNA Library Prep kit.

By the variant Caller module of the SMRT Link software, the arrow algorithm was used to correct and count the variant sites in the preliminary assembly results. SMRT cell data were generated and low-quality reads were filtered with SMRT link software (v5.0.1) (Ardui et al. 2018; Reiner et al. 2018). The preassembly was polished, using the arrow algorithm, by mapping raw long reads back to the preassembled genome. As a result, $14.92 \mathrm{~Gb}$ of long-read data were obtained, and the preliminary assembled genome length was $36 \mathrm{Mb}$. After the preassembled genome was polished, a genome sequence of $35.87 \mathrm{Mb}(416 \times$ genome coverage) was assembled into 33 contigs ( $\mathrm{N}_{50}$ value of $2.01 \mathrm{Mb}$ ) with maximum and average contig lengths of 3.39 and $1.09 \mathrm{Mb}$, respectively, and GC content of $47.75 \%$ (Table 1). Based on the reference of $V$. effusa isolate FRT5LL7 (Winter et al. 2020), we anchored and sorted our contigs to chromosomes by Chromosomer software (Tamazian

Vol. 34, No. 7, 2021 / 853 
et al. 2016). We concluded that $V$. carpophila had at least 19 chromosomes, which was similar to the number of identified for $V$. effusa isolate FRT5LL7 (20 chromosomes) (Winter et al. 2020). The completeness of the ZJHZ1-1-1 assembly was assessed using BUSCO v3.0 (Waterhouse et al. 2018). Genomic evaluation with the ascomycota $(n=1,315)$ and fungal dataset $(n=290)$ showed 97.5 and $97.6 \%$ completeness, respectively (Simão et al. 2015). Genomic annotation predicted the coding genes, repetitive sequences, and noncoding RNAs. We used the Augustus 2.7 program (Stanke et al. 2008) to retrieve the related coding genes, integrating the RNA-seq data of the isolate ZJHZ1-1-1. A total of 10,080 protein-coding genes were found by combining RNA-seq and de novo strategies, which is similar to the 10,820 genes predicted for $V$. effusa, of which 8,508 have at least one functional annotation (Winter et al. 2020). The circular representation of the complete genome of $V$. carpophila isolate ZJHZ1-1-1 is shown in Supplementary Figure S1. The interspersed repetitive sequences were predicted using RepeatMasker (Saha et al. 2008). SINE and LINE (short and long interspersed nuclear elements) repetitive sequences were $0.09 \%$. The tandem repeats were analyzed by the TRF (tandem repeats finder) (Benson 1999), which were 1\%. Seventy-five transfer RNA (tRNA) genes were predicted by the tRNAscan-SE (Lowe and Eddy 1997), having a total length of 6,928 bp. We used seven databases to predict gene functions, including Gene Ontology, Kyoto Encyclopedia of Genes and Genomes, Clusters of Orthologous Groups, Non-Redundant Protein Database databases, Transporter Classification Database, P450, and Swiss-Prot. Following a previous pipeline (Bao et al. 2017), gene annotation analysis revealed that 894 proteins had putative secretion signals and 699 candidate secreted proteins were identified. In addition, 214 proteins were associated with production of secondary metabolites (Table 1).

The draft genome sequence and annotation of $V$. carpophila isolate JP3-5 from the United States has been reported previously (MECS0000000) (Chen et al. 2017), the genome was sequenced with Illumina MiSeq plantform, and the genome sequence of $36.92 \mathrm{Mb}\left(263 \times\right.$ genome coverage) was assembled into 657 contigs ( $\mathrm{N}_{50}$ value of $0.31 \mathrm{Mb}$ ) with maximum and average contig lengths of 1.45 and $0.06 \mathrm{Mb}$, respectively. Based on the development of bioinformatics and the deeper sequencing compared with the V. carpophila JP3-5 genome assembly, V. carpophila ZJHZ1-1-1 genome assembly resulted in a higher-quality genome assembly and annotations. For example, the ZJHZ1-1-1 genome was assembled into 33 contigs $\left(N_{50}\right.$ value of $\left.2.01 \mathrm{Mb}\right)$ with maximum and average contig lengths of 3.39 and $1.09 \mathrm{Mb}$, respectively. The details of comparison are shown in Table 1. Although, other Venturia genomes, including V. carpophila, have been completely sequenced, ZJHZ1-1-1 represents the first fully sequenced $V$. carpophila genome from China. The outcome of this study will be a valuable resource for scientists working in the comparative genomics of scab pathogens. This will provide insights into the epidemiology, evolution, and population biology of the genus Venturia. Further, it will also be a useful resource for functional analysis of many important genes associated with fungicide resistance and pathogenicity.

Table 1. Whole-genome assembly statistics for Venturia carpophila isolates ZJHZ1-1-1 and JP3-5

\begin{tabular}{lll} 
Assembly parameters & ZJHZ1-1-1 & JP3-5 \\
Sequencing platform & $\begin{array}{l}\text { PacBio Sequel and Illumina } \\
\text { NovaSeq PE150 }\end{array}$ & Illumina MiSeq \\
Assembly method & SMRT Link v5.0.1 & \\
Assembly level & Contig & A5-Miseq v.1.0 \\
Genome size & $35.87 \mathrm{Mb}$ & Scaffold \\
Sequencing coverage & $416 \times$ & $36.92 \mathrm{Mb}$ \\
Number of contigs/scaffold & 33 & $263 \times$ \\
Average contig/scaffold length & $1.09 \mathrm{Mb}$ & 657 \\
Contig N & $2.01 \mathrm{Mb}$ & $0.06 \mathrm{Mb}$ \\
Maximum contig length & $3.39 \mathrm{Mb}$ & $0.31 \mathrm{Mb}$ \\
GC content \% & 47.75 & $1.45 \mathrm{Mb}$ \\
Genes & 10,080 & 47.40 \\
Candidate secreted proteins & 699 & 8,352 \\
Annotated genes & 8,508 & 390 \\
GenBank ID & JACTAK000000000 & 4,632 \\
\hline
\end{tabular}




\section{Data Availability}

The ITS and LSU sequences of ZJHZ1-1-1 have been submitted to the GenBank nucleotide database under accession numbers MN958609 and MT772296, respectively. Full genome-assembly data and genome annotations were deposited in the National Center for Biotechnology Information database under BioProject PRJNA642010, BioSample SAMN15375461, and SRA accessions SRR12095801 and SRR12095802 for Illumina and PacBio data, respectively. This whole-genome shotgun project has been deposited in the DDBJ/ENA/GenBank database under accession JACTAK000000000.

\section{Acknowledgments}

We thank G. Zhu, X. Gu, H. Song, C. Xu, L. Gao, J. Zhao, and H. Chen from Changli Fruit Research Institute, T. Zhang (Beijing Academy of Agriculture and Forestry Sciences), G. Chen (Southwest University), and X. Huang (Huazhong Agricultural University) for assisting with sample collection.

\section{Author-Recommended Internet Resource}

Arrow algorithm: https://github.com/pacificbiosciences/genomicconsensus

\section{Literature Cited}

Ardui, S., Ameur, A., Vermeesch, J. R., and Hestand, M. S. 2018. Single molecule real-time (SMRT) sequencing comes of age: Applications and utilities for medical diagnostics. Nucleic Acids Res. 46:2159-2168.

Bao, J., Chen, M., Zhong, Z., Tang, W., Lin, L., Zhang, X., Jiang, H., Zhang, D., Miao, C., Tang, H., Zhang, J., Lu, G., Ming, R., Norvienyeku, J., Wang, B., and Wang, Z. 2017. PacBio sequencing reveals transposable elements as a key contributor to genomic plasticity and virulence variation in Magnaporthe oryzae. Mol. Plant 10:1465-1468.

Bensch, K., Ritschel, A., and Braun, U. 2003. A monograph of Fusicladium s.lat. (Hyphomycetes). Schlechtendalia (Halle) 9:1-132.

Benson, G. 1999. Tandem repeats finder: A program to analyze DNA sequences. Nucleic Acids Res. 27:573-580.

Bock, C. H., Chen, C., Yu, F., Stevenson, K. L., and Wood, B. W. 2016. Draft genome sequence of Fusicladium effusum, cause of pecan scab. Stand. Genomic Sci. 11:36.

Chen, C., Bock, C. H., Brannen, P. M., and Adaskaveg, J. E. 2018. Mining and characterization of microsatellites from a genome of Venturia carpophila. Mycol. Prog. 17:885-895.

Chen, C., Bock, C. H., Brannen, P. M., Adaskaveg, J. E., Hotchkiss, M. W., Brewer, M. T., and Wood, B. W. 2014. Genetic variability among populations of Fusicladium species from different host trees and geographic locations in the USA. Mycol. Prog. 13:1006.

Chen, C., Bock, C. H., and Wood, B. W. 2017. Draft genome sequence of Venturia carpophila, the causal agent of peach scab. Stand. Genomic Sci. 12:68.

Cooke, I. R., Jones, D., Bowen, J. K., Deng, C., Faou, P., Hall, N. E., Jayachandran, V., Liem, M., Taranto, A. P., Plummer, K. M., and Mathivanan, S. 2014. Proteogenomic analysis of the Venturia pirina (pear scab fungus) secretome reveals potential effectors. J. Proteome Res. 13:3635-3644.

Fisher, E. E. 1961. Venturia carpophila sp.nov., the ascigerous state of the apricot freckle fungus. Trans. Br. Mycol. Soc. 44:337-IN4.

Goh, T. K. 1999. Single-spore isolation using a hand-made glass needle. Fungal Divers. 2:47-63

González-Domínguez, E., Armengol, J., and Rossi, V. 2017. Biology and epidemiology of Venturia species affecting fruit crops: A review. Front. Plant Sci. 8:1496.

Jaber, M. Y., Bao, J., Gao, X., Zhang, L., He, D., Wang, X., Wang, A., Wang, Z., and Wang, B. 2020. Genome sequence of Venturia oleaginea, the causal agent of olive leaf scab. Mol. Plant-Microbe Interact. 33:1095-1097.

Johnson, S., Jones, D., Thrimawithana, A. H., Deng, C. H., Bowen, J. K., Mesarich, C. H., Ishii, H., Won, K., Bus, V. G. M., and Plummer, K. M. 2019. Whole genome sequence resource of the Asian pear scab pathogen Venturia nashicola. Mol. Plant-Microbe Interact. 32:1463-1467.
Kim, G. H., Jo, K. Y., Shin, J. S., Shin, G. H., and Koh, Y. J. 2017. Epidemiological characteristics of scab of Japanese apricot in Korea. Plant Pathol. J. 33:450-457.

Le Cam, B., Sargent, D., Gouzy, J., Amselem, J., Bellanger, M. N., Bouchez, O., Brown, S., Caffier, V., De Gracia, M., Debuchy, R., Duvaux, L., Payen, T., Sannier, M., Shiller, J., Collemare, J., and Lemaire, C. 2019. Population genome sequencing of the scab fungal species Venturia inaequalis, Venturia pirina, Venturia aucupariae and Venturia asperata. G3 (Bethesda) 9:24052414.

Lichtner, F. J., Jurick, W. M., 2nd, Ayer, K. M., Gaskins, V. L., Villani, S. M., and Cox, K. D. 2020. A genome resource for several North American Venturia inaequalis isolates with multiple fungicide resistance phenotypes. Phytopathology 110:544-546.

Lowe, T. M., and Eddy, S. R. 1997. tRNAscan-SE: A program for improved detection of transfer RNA genes in genomic sequence. Nucleic Acids Res. 25:955-964.

Hu, X. P., Yang, J. R., Shang, W. J., and Yang, Z. W. 2004. Study on the method for DNA extraction of Venturia inaequalis. J. Northwest ScienceTechnology University of Agriculture and Forestry 32:41-43.

Reiner, J., Pisani, L., Qiao, W., Singh, R., Yang, Y., Shi, L., Khan, W. A., Sebra, R., Cohen, N., Babu, A., Edelmann, L., Jabs, E. W., and Scott, S. A. 2018. Cytogenomic identification and long-read single molecule real-time (SMRT) sequencing of a Bardet-Biedl syndrome 9 (BBS9) deletion. NPJ Genom. Med. 3:3.

Saha, S., Bridges, S., Magbanua, Z. V., and Peterson, D. G. 2008. Empirical comparison of ab initio repeat finding programs. Nucleic Acids Res. 36:22842294.

Scherm, H., Savelle, A. T., Boozer, R. T., and Foshee, W. G. 2008. Seasonal dynamics of conidial production potential of Fusicladium carpophilum on twig lesions in Southeastern peach orchards. Plant Dis. 92:47-50.

Schnabel, G., and Layne, D. R. 2004. Comparison of reduced-application and sulfur-based fungicide programs on scab intensity, fruit quality, and cost of disease control on peach. Plant Dis. 88:162-166.

Schubert, K., and Braun, U. 2004. Taxonomic revision of the genus Cladosporium s. lat. 2. Morphotaxonomic examination of Cladosporium species occurring on hosts of the families bignoniaceae and orchidaceae. Sydowia 56:76-97.

Shiller, J., Van de Wouw, A. P., Taranto, A. P., Bowen, J. K., Dubois, D., Robinson, A., Deng, C. H., and Plummer, K. M. 2015. A large family of AvrLm6-like genes in the apple and pear scab pathogens, Venturia inaequalis and Venturia pirina. Front. Plant Sci. 6:980.

Simão, F. A., Waterhouse, R. M., loannidis, P., Kriventseva, E. V., and Zdobnov, E. M. 2015. BUSCO: Assessing genome assembly and annotation completeness with single-copy orthologs. Bioinformatics 31:3210-3212. 
Stanke, M., Diekhans, M., Baertsch, R., and Haussler, D. 2008. Using native and syntenically mapped cDNA alignments to improve de novo gene finding. Bioinformatics 24:637-644.

Tamazian, G., Dobrynin, P., Krasheninnikova, K., Komissarov, A., Koepfli, K.-P., and O'Brien, S. J. 2016. Chromosomer: A reference-based genome arrangement tool for producing draft chromosome sequences. Gigascience 5:38.

Vilgalys, R., and Hester, M. 1990. Rapid genetic identification and mapping of enzymatically amplified ribosomal DNA from several Cryptococcus species. J. Bacteriol. 172:4238-4246.

Waterhouse, R. M., Seppey, M., Simão, F. A., Manni, M., loannidis, P., Klioutchnikov, G., Kriventseva, E. V., and Zdobnov, E. M. 2018. BUSCO applications from quality assessments to gene prediction and phylogenomics. Mol. Biol. Evol. 35:543-548.

White, T. J., Bruns, T., Lee, S., and Taylor, J. 1990. Amplification and direct sequencing of fungal ribosomal RNA genes for phylogenetics. Pages 315-322 in: PCR Protocols: A Guide to Methods and Applications. M. A. Innis, D. H. Gelfand, J. J. Sninsky, and T. J. White, eds. Academic Press, San Diego, CA, U.S.A.

Winter, D. J., Charlton, N. D., Krom, N., Shiller, J., Bock, C. H., Cox, M. P., and Young, C. A. 2020. Chromosome-level reference genome of Venturia effusa, causative agent of pecan scab. Mol. Plant-Microbe Interact. 33:149-152.

Zhou, Y., Fan, F., Wang, L., Chaisiri, C., Yin, L.-F., Yin, W.-X., and Luo, C.-X. 2021 Development of a loop-mediated isothermal amplification method for the rapid detection of Venturia carpophila on peach. Pest Manag. Sci. 77:1383-1391. 